\title{
Bladder-sparing protocols in the treatment of muscle-invasive bladder cancer
}

\author{
Côme Tholomier $^{1}$, Luis Souhami ${ }^{2}$, Wassim Kassouf ${ }^{1}$ \\ ${ }^{1}$ Department of Surgery, Division of Urology, McGill University, McGill University Health Centre, Montréal, Québec, Canada; ${ }^{2}$ Department of \\ Radiation Oncology, McGill University, McGill University Health Centre, Montréal, Québec, Canada \\ Contributions: (I) Conception and design: All authors; (II) Administrative support: All authors; (III) Provision of study materials or patients: All \\ authors; (IV) Collection and assembly of data: All authors; (V) Data analysis and interpretation: All authors; (VI) Manuscript writing: All authors; (VII) \\ Final approval of manuscript: All authors. \\ Correspondence to: Dr. Wassim Kassouf. McGill University Health Centre, 1001 Decarie Blvd, Montréal, QC, H4A 3J1, Canada. \\ Email: wassim.kassouf@muhc.mcgill.ca.
}

\begin{abstract}
Bladder-sparing protocols (BSP) have been gaining widespread popularity as an attractive alternative to radical cystectomy (RC) for muscle-invasive bladder cancer. Unimodal therapies are inferior to multimodal regimens. The most promising regimen is trimodal therapy (TMT), which is a combination of maximal transurethral resection of bladder tumor (TURBT), radiotherapy, and chemotherapy. In appropriately selected patients (low volume unifocal T2 disease, complete TURBT, no hydronephrosis and no carcinoma-in-situ), comparable oncological outcomes to RC have been reported in large retrospective studies, with a potential improvement in overall quality of life (QOL). TMT also offers the possibility for definitive therapy for patients who are not surgically fit to undergo RC. Routine biopsy of previous tumor resection is recommended to assess response. Prompt salvage RC is required in non-responders and for recurrent muscle-invasive disease, while non-muscle-invasive recurrence can be managed conservatively with TURBT +/- intravesical BCG. Long-term follow-up consisting of routine cystoscopy, urine cytology, and cross-section imaging is required. Further studies are warranted to better define the role of neoadjuvant or adjuvant chemotherapy in the setting of TMT. Finally, future research on predictive markers of response to TMT and on the integration of immunotherapy in bladder sparing protocols is ongoing and is highly promising.
\end{abstract}

Keywords: Muscle-invasive bladder cancer; chemoradiation; trimodal therapy (TMT); bladder-sparing protocols (BSP); bladder preservation therapy; transurethral resection of bladder tumor (TURBT)

Submitted Sep 07, 2019. Accepted for publication Nov 29, 2019.

doi: $10.21037 /$ tau.2020.02.10

View this article at: http://dx.doi.org/10.21037/tau.2020.02.10

\section{Introduction}

Bladder cancer is the $10^{\text {th }}$ most common cancer worldwide with an estimated 550,000 new cases and 200,000 deaths in 2018 (1). About $25 \%$ of new diagnoses are muscle-invasive bladder cancer (MIBC), which carry a worse prognosis compared to non-muscle invasive disease (2). Neoadjuvant chemotherapy (NAC) followed by radical cystectomy (RC) with bilateral pelvic lymphadenectomy is considered the standard of care for treatment of MIBC by multiple international guidelines (3-5). However, this is associated with a significant impact on quality of life (QOL) as RC affects continence, sexual function, fertility, and bowel function. Moreover, many elderly individuals, which represents most of bladder cancer patients, may not be surgical candidates due to associated medical co-morbidities (6). Indeed, RC carries a rate of high-grade complications of $20 \%$ and a mortality risk of $3-6 \%$, which increases up to $8-14 \%$ for patients over 80 years old (7-11). This may explain why approximately $50 \%$ of patients with invasive 
disease receive no definite treatment (12).

Bladder-sparing protocols (BSP) answer an unmet need to broaden treatment options for patients with MIBC, with the ultimate goal of preserving optimal QOL, avoiding risks of mortality and morbidity of RC while maintaining appropriate oncological control. Multiple regimens are available, including unimodal chemotherapy or radiotherapy, maximal transurethral resection of bladder tumor (TURBT) or partial cystectomy, and multimodal protocols (chemoradiation or trimodal therapy, TMT); the latter being the most promising and the most commonly used approach. It involves a combination of maximal TURBT and concomitant chemoradiation.

\section{Unimodal therapy}

It is important to note that all unimodal therapies are inferior to combination therapy or RC and therefore should not be routinely offered alone as a curative intent. This is emphasized in international guidelines (3-5).

\section{TURBT}

TURBT alone could be therapeutic only if the tumor is limited to the superficial muscle layer and if repeat biopsies of the previous resection site are negative for invasive tumor (i.e., no residual T1 or higher stage disease). Solsona et al. reported on a phase II study for MIBC with 15-year of follow-up on 133 highly-selected patients who were treated with a complete TURBT with negative biopsy posttreatment (13). The 5-, 10- and 15-year overall survival (OS) and cancer-specific survival (CSS) rates were $73.7 \%$, $39.8 \%, 24.8 \%$ and $81.9 \%, 79.5 \%, 76.7 \%$, respectively. Their rate of disease progression was $30 \%$, with $7.7 \%$ of patients developing metastasis. Of interest, $100 \%$ of patients who developed metastasis occurred during the first 36 months post TURBT, and only $30 \%$ of patients had local progression from 36 to 180 months (and none after this period). Their follow-up schedule that was developed consists of endoscopic and systemic evaluation every 3 months during the first 3 years, after which systemic evaluation can be omitted and endoscopic interval can be prolonged to every 6 months for 5 years, then annually up to 15 years. Herr reported similar survival rates with 10 year CSS of $76 \%$ for 99 patients who received TURBT alone for patients with MIBC (14). Patients with T0 disease on restaging TUR were significantly more likely to survive than patients with $\mathrm{T} 1$ disease $(82 \%$ vs. $57 \%, \mathrm{P}=0.003)$.
Optimal characteristics for patients undergoing TURBT alone in MIBC are the following: accessible tumor location, complete resection with a negative restaging TURBT, tumor size $<2-3 \mathrm{~cm}$, no multi-focal carcinoma in-situ (CIS), no hydronephrosis, and adequate bladder function $(13,14)$.

\section{Partial cystectomy}

In highly selected patients, partial cystectomy alone for MIBC has been reported to provide reasonable oncological outcomes, with the added advantage of accurate staging by lymphadenectomy and full-thickness resection with adequate evaluation of surgical margins compared to TURBT alone. Capitanio et al. reported a comparable 5 -year OS and CSS for partial cystectomy and RC of 57\% and $70 \%$ compared to $55 \%$ and $69 \%$, respectively, when patients were matched for age, race, TNM stage, tumor grade and number of lymph nodes removed (15). However, the recurrence rates after partial cystectomy reported in the literature have been as high as $38-49 \%$ with up to $30 \%$ of patients ultimately undergoing RC (15-17).

Ideal candidates are patients with a solitary lesion $<3-$ $4 \mathrm{~cm}$, where excision with $2-\mathrm{cm}$ margins is feasible (such as the bladder dome), no concomitant CIS, no need for ureteral reimplantation, and no hypercontractility of the bladder (18). Less than $5 \%$ of MIBC population would meet the criteria for partial cystectomy (16).

\section{Chemotherapy}

NAC was shown to lead to downstaging in some patients, with $30 \%$ to $40 \%$ of patients having no residual disease at time of RC (19-21). Herr et al. reported on a cohort of 63 patients who refused RC after complete response (CR) following NAC (22). CR was defined as negative post-chemotherapy TUR biopsy and imaging showing radiographic resolution of the tumor. The 5-year OS was 64\%; however, the relapse rate was relatively high at $64 \%$, with $38 \%$ (24 patients) of recurrence being muscle-invasive. The median time to muscle-invasive recurrence was 16 months. In total, 19 patients (30\%) with muscle-invasive relapse died of their disease; however, 10 patients refused RC even after invasive recurrence, where RC could have salvaged oncological outcomes and prevented bladder cancer death. Solsona et al. published a phase 2 nonrandomized trial in selected patients with residual microscopic disease after complete TURBT and offered either chemotherapy or RC (23). The 5- and 10-year CSS rate were $65 \%$ and $60 \%$, respectively, which was similar to the $\mathrm{RC}$ arm. However, a high proportion of patients developed 
invasive recurrence or metastasis (29\%) and required salvage RC ( $45 \%) ; 10 \%$ of patients with initial bladder preservation developed distant metastasis without local recurrence and later died of their disease.

Finally, a more recent retrospective study conducted by Mazza et al. reported on 148 patients who elected for active surveillance after clinical CR to TURBT and NAC (24). They reported a 5 -year OS of $86 \%$, a relapse rate of $48 \%$, with $23 \%$ of recurrence being muscle-invasive. All these patients had a rigorous follow-up regimen and most had a low-risk disease (cT2 disease, solitary and $<5 \mathrm{~cm}$ tumor, no hydronephrosis and no CIS). They were also offered salvage cystectomy at time of recurrence. In their cohort, $7 \%$ of patients developed a local recurrence and then metastasized, which could have potentially been prevented with upfront $\mathrm{RC}$. This is similar to what has been previously reported, with an added mortality risk between $7 \%$ and $16 \%$ when a patient elect to undergo BSP compared to upfront RC (25).

\section{Radiotherapy}

External beam radiotherapy (EBRT) has been shown to lead to complete regression of MIBC in up to $70 \%$ of patients, with a sustained local response of $30-50 \%$; however, more than $50 \%$ of individuals will develop metastatic disease and 5-year OS is only 20-30\% (26). James et al. reported a 2 -year disease-free survival rate of $54 \%$ and a 5 -year OS of $35 \%$ in their radiotherapy alone group (27). Patients with T3-4 disease, extravesical mass, large tumor size $(>5 \mathrm{~cm}$ ), and hydronephrosis were more likely to have an incomplete response or local recurrence. On the other hand, pre-radiotherapy maximal TURBT and the absence of CIS were good prognostic factors. The development of modern radiotherapy equipment and the introduction of sophisticated computer technology have improved the accuracy of planning and the precision of treatment delivery leading to a decreased radiotherapy toxicity rate. The use of intensity modulated and image-guided EBRT results in less than $10 \%$ of major late genitourinary or gastrointestinal toxicities $(28,29)$. Usually, doses of 50 to $70 \mathrm{~Gy}$ are given in 1.8 to 2.5 Gy daily fractions over a course of 4 to 7 weeks to the bladder tumor, while 40 to 50 Gy are usually delivered to the pelvic lymph nodes.

Combined chemoradiotherapy has been shown to be significantly superior to radiotherapy alone, with a twoyear OS of $56 \%$ vs. $42 \%$ for EBRT (30). Moreover, a Cochrane review from 2002 demonstrated that RC had also a significant OS benefit compared to radiotherapy alone:
$36 \%$ vs. $20 \%$ at 5 years (31). Therefore, EBRT alone results in inferior oncological outcomes compared to either RC or multimodal therapy and should not be used alone as primary therapy. However, in frail individuals who are otherwise not candidate for concurrent chemotherapy or RC, cure can still be achievable in patients treated with radiation alone.

\section{Multimodal BSP: TMT}

\section{Maximal TURBT}

The initial step of any multimodal treatment is a "maximal TURBT", where as much tumor as possible should be safely resected. The goal is to remove all visible disease without compromising the safety of the procedure. It has been shown in multiple prospective studies that the rate of local control was $20 \%$ higher if a complete resection was achieved $(32,33)$. Therefore, patients with large T3/ T4 tumors or multifocal CIS, which cannot be completely resected by TURBT, are less likely to be cured by such multi-modal approach (34).

\section{Chemotherapy}

Chemotherapy serves two purposes. First, it will act as a sensitizer to radiation by increasing cell kill in a synergistic fashion. Second, it can potentially improve loco-regional control, as up to $50 \%$ of patients with MIBC may have occult metastases $(4,35)$.

Several chemotherapy regimens have been used in combination with EBRT. However, only few randomized controlled trials (RCTs) have compared combined chemoradiotherapy $v$ s. radiotherapy alone. Supporting evidence from RCTs using the combined approach exists for cisplatin and mitomycin C plus 5-fluorouracil $(27,36)$. Concurrent cisplatin and EBRT was shown to reduce pelvic relapse rate (hazards ratio $0.50, \mathrm{P}=0.036$ ) compared to EBRT alone; however, no impact on OS was seen. Multiple other retrospective studies reported similar results $(37,38)$. Concomitant mitomycin $\mathrm{C}$ plus 5 -FU and radiation was shown to significantly improve locoregional disease-free survival and lower the rate of salvage RC in the BC2001 phase III trial; however, no impact on CSS or OS was demonstrated (5-year OS of 48\% in the chemoradiotherapy group $v s .35 \%$ with radiotherapy alone, $\mathrm{P}=0.16)(27,39)$.

Gemcitabine with once daily radiation in a phase 2 randomized trial was recently shown to be well tolerated while producing a high and durable response rate (3-year 
CSS and OS were $82 \%$ and $75 \%$, respectively), which was comparable to cisplatin plus 5-FU with twice-a-day radiation (40). A randomized trial assessing hypoxiamodifying agents (radiotherapy with concurrent carbogen and nicotinamide) demonstrated a significant improvement in OS and local relapse for combination therapy with a 3-year OS of $59 \%$ vs. $46 \%$ for radiotherapy alone (41). These options are particularly useful when patients are not eligible for cisplatin (42). International guidelines recommend the use of either cisplatin, gemcitabine, or mitomycin plus 5-FU for radiation sensitizing chemotherapy as most evidence exists for these regimens (3-5).

\section{Radiotherapy}

Standard radiation regimen usually involves EBRT to the bladder and pelvic lymph nodes for an initial dose of $40 \mathrm{~Gy}$, followed by additional boost to the bladder to 54 Gy and a final boost to the tumor to 64-65 Gy (43). The RTOG 0712 reported on the feasibility of twice daily radiation with $5-\mathrm{FU}$ and cisplatin or once daily radiation with gemcitabine (44). Both regimens were found to have appropriate and comparable oncological outcomes, while the once daily regimen was associated with less grade 3 and 4 toxicities: (55\% vs. 64\%). Over the last few years, radiotherapy regimens using hypofractionated EBRT have been developed, limiting overall treatment duration, and providing similar outcomes in terms of toxicity and disease control $(29,40)$. Total doses ranging from 50 to 52.5 Gy in 20 fractions given over 4 weeks are delivered usually in combination with weekly gemcitabine.

Controversy exists on whether partial bladder radiation (with a boost to the tumor region) provides the same outcomes as whole bladder radiation, while sparing normal tissue and decreasing toxicity at the potential cost of missing occult tumor not seen by cystoscopy or imaging. One small retrospective study and another prospective trial did not show neither statistical significance in local recurrence nor OS, but with similar treatment toxicity $(45,46)$. The BC2001 trial also reported on a reduced radiation treatment volume, which aimed to spare the uninvolved bladder (receiving up to $80 \%$ of maximum dose) while delivering full dose to the tumor (47). They showed no statistically significant differences in grade $3 / 4$ acute or late toxicity ( $20 \%$ vs. $25 \%, \mathrm{P}=0.48$ and $2.4 \%$ vs. $5.4 \%, \mathrm{P}=0.47$, for standard radiotherapy $v s$. reduced volume, respectively). Although both groups had similar 5-year OS (38\% vs. $44 \%$, respectively), the study could not establish a non- inferiority outcome of locoregional recurrence-free rate at 2 years $(61 \%$ vs. $64 \%, \mathrm{P}=0.36)$ for the limited volume arm. Therefore, both options seem to have similar efficacy and toxicity rates and may be used for BSP in selected patients. Large multi-institutional RCTs are required to validate these results.

Another area of interest in radiotherapy is the extent of nodal irradiation. Pelvic nodal involvement in muscleinvasive disease is present in at least $30 \%$ of patients (48). Furthermore, several studies reported that $20-30 \%$ of patients with lymph node metastasis are cured with RC plus pelvic lymphadenectomy $(49,50)$. Thus, at this point, it is recommended to include pelvic nodal radiation in BSP until larger randomized trials can better evaluate the clinical impact of omitting pelvic radiation.

Of interest, two small randomized trials (230 and 60 patients, respectively) compared whole pelvis radiation $v s$. bladder only radiation and reported no difference in neither local disease control nor OS, while decreasing acute toxicities by avoiding nodal irradiation $(51,52)$. The rate of acute grade 3 or 4 toxicity reported by Tunio et al. was $13.3 \%$ in the bladder-only group compared to $17.6 \%$ in the whole pelvis radiation group $(\mathrm{P}=0.05)$. Arafat et al. reported similar rate of acute genitourinary toxicity in both groups, but a significantly higher rate of acute gastrointestinal toxicity (grades 1-4) in the whole pelvis group (93.3\% vs. $16.7 \%)$. Severe RTOG grades 3-4 gastrointestinal toxicity was reported in $6.7 \%$ and $0 \%$, respectively. There was no difference in late toxicity between the two groups.

Centers delivering radiotherapy using a "split course" regimen advocate for cystoscopic assessment and biopsy of the previous tumor site or any suspicious lesion after an initial radiotherapy dose of 40 Gy is given $(4,53)$. If incomplete response is observed, patients undergo immediate salvage RC. If no evidence of disease is present, then a consolidative course of radiotherapy is used. A "continuous" regimen is another option used by many centers, where the full dose of radiotherapy is given and cystoscopic evaluation with biopsy is done only 1 to 3 months later (27). No prospective trial comparing these options has been done and no evidence exists that one approach is superior to the other in terms of improving survival or decreasing toxicity.

\section{Patient selection for TMT}

As mentioned earlier, patient selection is of paramount importance for successful oncologic control in BSP. Multiple centers have shown improved outcomes as they 
Table 1 Ideal selection criteria for trimodal therapy

\begin{tabular}{ll}
\hline Ideal TMT patient* $^{\star}$ & Non-ideal TMT patient (high-risk features) $^{\star}$ \\
\hline cT2 & cT3-cT4a disease \\
Complete TURBT & Inability to perform complete TURBT \\
No hydronephrosis & Presence of hydronephrosis \\
No CIS & Presence of extensive CIS \\
Unifocal tumor & Diffuse and multifocal disease \\
Good bladder function and capacity & \\
\hline
\end{tabular}

*, to be considered an ideal TMT, all characteristics need to be present and no high-risk features. TMT, trimodal therapy; TURBT, transurethral resection of bladder tumor; CIS, carcinoma-in-situ.

refined their selection criteria. For example, Giacalone et al. (34) improved the 5 -year OS for TMT over time from $53 \%$ to $75 \%$ and diminished their rate of salvage RC from $29 \%$ to $16 \%$ by being more selective (100\% without hydronephrosis, $97 \%$ cT2, $82 \%$ had maximal TURBT, $81 \%$ without CIS, $73 \%$ had adjuvant chemotherapy). On their multivariate analysis, T2 disease, CR to chemoradiation, hydronephrosis, and presence of CIS were significant predictors for OS with hazards ratio (HR) of 0.57, 0.61, 1.51 and 1.56 , respectively. Complete TURBT was a predictor for bladder-intact disease-specific survival (HR 0.72). Our experience also showed that TMT outcomes were better as we refined our selection criteria in elderly patients: 3 -year CSS improved from $38 \%$ to $71 \%(29,54)$.

Table 1 lists the oncological factors that define patients as ideal or non-ideal candidates for TMT. The high-risk features associated with worse outcomes with TMT are the following: incomplete/inability to perform maximal TURBT, presence of extensive CIS, hydronephrosis, diffuse multifocal disease, and cT3-cT4a disease. TMT would still be feasible in patients with high-risk features, but chance of cure is significantly diminished.

\section{Outcomes of TMT}

\section{CSS and OS}

A systematic review performed in 2014 reported a 5 -year CSS for TMT ranging from $50 \%$ to $82 \%$, and a 5 -year OS of approximately $50 \%$, ranging from $36 \%$ to $74 \%$ (55). Discrepancies in results are expected as patient selection, chemotherapy, radiotherapy regimens, as well as use of neoadjuvant or adjuvant chemotherapy varied in the literature. Pooled analysis from six RTOG bladder- preservation studies had a 5 -year CSS of $71 \%$, a 5 -year OS of $57 \%$, and a $21 \%$ rate of salvage RC (56). The largest single-center experience reported a 5 -year CSS of $66 \%$ and a 5 -year OS of $57 \%$ (34). These results are similar to contemporary RC cohorts reporting a 5-year OS of 57\% (50). Table 2 summarizes major findings of various TMT series.

Similar to TMT, improved outcomes can be seen in patients treated with $\mathrm{RC}$ as the selection criteria are refined. Culp et al. reported a 5 -year OS of $64.8 \%$ and a 5 -year CSS of $83.5 \%$ for low-risk patients (i.e., <cT3b disease, no hydronephrosis, no palpable mass, no lymphovascular invasion on TURBT) who underwent RC (72). Therefore, direct comparison between TMT and RC is difficult, as there is an inherent strong bias of choosing one therapy over the other and patient selection is vastly different. Randomized trials are required to obtain similar patient population to allow comparison of both modalities.

Two RCTs exist, which directly compare TMT to RC. A small single-centre RCT, which was conducted in Egypt and consisted of 160 patients, showed no difference in OS between RC and TMT (3-year OS of $63 \%$ and $61 \%$ respectively) (57). No NAC was given and a salvage RC rate of $33 \%$ was reported. However, even though the histologic type is not reported, $71 \%$ of patients had a history of schistosomiasis, which is associated with higher risk of developing squamous cell carcinoma of the bladder rather than urothelial cell carcinoma. This potentially prevents the applicability of this study to most MIBC patients. Another trial, the SPARE trial aimed to compare RC and BSP in a multicentre RCT setting, but failed to recruit as initially planned (73). In 30 months, only 25 patients were randomized to RC and 20 to TMT. This was mostly caused by clinician and patient preferences for treatment, which prevented proper randomization of treatment allocation 
Table 2 Trimodal therapy outcomes based on modern published clinical studies with more than 50 patients

\begin{tabular}{|c|c|c|c|c|c|c|c|c|c|}
\hline Study & $\begin{array}{l}\text { Median } \\
\text { follow-up } \\
\text { (months) }\end{array}$ & $\begin{array}{l}\text { No. of } \\
\text { patients }\end{array}$ & Inclusion criteria & $\begin{array}{l}\text { Neoadjuvant } \\
\text { or adjuvant } \\
\text { chemotherapy }\end{array}$ & $\begin{array}{l}\text { Concomitant } \\
\text { chemotherapy }\end{array}$ & Radiotherapy & CR rate & $\begin{array}{c}\text { Salvage } \\
\text { RC }\end{array}$ & Survival \\
\hline $\begin{array}{l}\text { AlGizawy } \\
\text { et al. [2014] } \\
(57)\end{array}$ & 27 & 80 & $\begin{array}{l}\text { T2-3, N0, M0; } \\
\text { complete TUR: } 60 \% \text {; } \\
\text { hydronephrosis: N/A }\end{array}$ & None & $\begin{array}{c}\text { Cisplatin + } \\
\text { gemcitabine } \\
(2 \text { cycles })\end{array}$ & $\begin{array}{c}46 \text { Gy }+20 \text { Gy if } \\
\text { initial CR }\end{array}$ & $83.8 \%$ & $32.5 \%$ & $\begin{array}{l}\text { 3-yr OS: } \\
61 \% ; 3-y r \\
\text { CSS: } 69 \%\end{array}$ \\
\hline $\begin{array}{l}\text { Tunio et al. } \\
\text { [2012] (52) }\end{array}$ & 60 & 230 & $\begin{array}{l}\text { T2-T4, N0, M0; } \\
\text { complete TUR: } 76.5 \% \text {; } \\
\text { hydronephrosis: } 30 \%\end{array}$ & None & $\begin{array}{c}\text { Cisplatin } \\
\text { weekly x6 }\end{array}$ & 65 Gy & $80.7 \%$ & $21.3 \%$ & $\begin{array}{l}\text { 5-yr OS: } \\
52 \% ; 5-y r \\
\text { CSS: } 47 \%\end{array}$ \\
\hline $\begin{array}{l}\text { Housset } \\
\text { et al.[1993] } \\
\text { (59) }\end{array}$ & 27 & 54 & $\begin{array}{l}\text { T2-T4, N0-N1; } \\
\text { complete TUR: 46\%; } \\
\text { hydronephrosis: } 42.6 \%\end{array}$ & None & $\begin{array}{l}5-F U+ \\
\text { cisplatin }\end{array}$ & 44 Gy & $79.6 \%$ & $27.8 \%{ }^{1}$ & $\begin{array}{l}\text { 3-yr OS: } \\
59 \% ; 3-y r \\
\text { CSS: } 62 \%\end{array}$ \\
\hline \multicolumn{10}{|l|}{ Phase 2 studies } \\
\hline $\begin{array}{l}\text { Coen et al. } \\
\text { [2019] (44) }\end{array}$ & 51.6 & 66 & $\begin{array}{l}\text { T2-T4a, Nx, M0; } \\
\text { complete TUR: N/A; } \\
\text { hydronephrosis: 0\% }\end{array}$ & Adjuvant: GC & $\begin{array}{c}5-\mathrm{FU}+ \\
\text { cisplatin or } \\
\text { gemcitabine }\end{array}$ & $\begin{array}{c}40 \text { Gy }+24 \text { Gy if } \\
\text { initial CR }\end{array}$ & $83.3 \%$ & $12.1 \%$ & $\begin{array}{l}\text { 3-yr OS: } \\
83.3 \%\end{array}$ \\
\hline $\begin{array}{l}\text { Mitin et al. } \\
\text { [2013] (60) }\end{array}$ & 60 & 93 & $\begin{array}{l}\text { T2-T4a, Nx, M0; } \\
\text { complete TUR: N/A; } \\
\text { hydronephrosis: } 0 \%\end{array}$ & $\begin{array}{l}\text { Adjuvant: GC } \\
\text { + paclitaxel } \\
(60 \%)\end{array}$ & $\begin{array}{c}\text { Paclitaxel + } \\
\text { cisplatin } \\
(49 \%) ; 5-F U+ \\
\text { cisplatin (51\%) }\end{array}$ & $\begin{array}{l}40.3 \text { Gy }+24 \text { Gy } \\
\text { if CR or near CR }\end{array}$ & $\begin{array}{l}67 \% \\
86 \% 2\end{array}$ & $5.4 \%$ & $\begin{array}{c}\text { 5-yr OS: } \\
73 \%\end{array}$ \\
\hline $\begin{array}{l}\text { Kaufman } \\
\text { et al. [2009] } \\
\text { (33) }\end{array}$ & 49.4 & 80 & $\begin{array}{l}\text { T2-T4a, NO, M0; } \\
\text { complete TUR: N/A; } \\
\text { hydronephrosis: 0\% }\end{array}$ & $\begin{array}{c}\text { Adjuvant: } \\
\text { paclitaxel + } \\
\text { gemcitabine } \\
(70 \%)\end{array}$ & $\begin{array}{l}\text { Paclitaxel + } \\
\text { cisplatin }\end{array}$ & $\begin{array}{c}40.3 \text { Gy + } 24 \text { Gy } \\
\text { if CR2 }\end{array}$ & $81 \%^{2}$ & $12.5 \%$ & $\begin{array}{l}\text { 5-yr OS: } \\
\text { 56\%; 5-yr } \\
\text { CSS: } 71 \%\end{array}$ \\
\hline $\begin{array}{l}\text { Gogna et al. } \\
\text { [2006] (62) }\end{array}$ & 23 & 113 & $\begin{array}{l}\text { T2-T4a, <10 cm tumor; } \\
\text { complete TUR: } 21.2 \% \text {; } \\
\text { hydronephrosis: N/A }\end{array}$ & None & $\begin{array}{l}\text { Cisplatin } \\
\text { weekly }\end{array}$ & 64 Gy & $70 \%$ & $13.3 \%$ & $\begin{array}{c}\text { 5-yr CSS: } \\
50 \%\end{array}$ \\
\hline $\begin{array}{l}\text { Kragelj et al. } \\
\text { [2005] (63) }\end{array}$ & 136 & 84 & $\begin{array}{l}\text { T1-T4, M0; complete } \\
\text { TUR: } 66.7 \% \text {; } \\
\text { hydronephrosis: } 14.3 \%\end{array}$ & None & $\begin{array}{l}\text { Vinblastine } \\
\text { weekly }\end{array}$ & 63.8-64 Gy & $78 \%$ & $4.8 \%^{3}$ & $\begin{array}{l}\text { 9-yr OS: } \\
\text { 25\%; 9-yr } \\
\text { CSS: } 51 \%\end{array}$ \\
\hline
\end{tabular}

Table 2 (continued) 
Table 2 (continued)

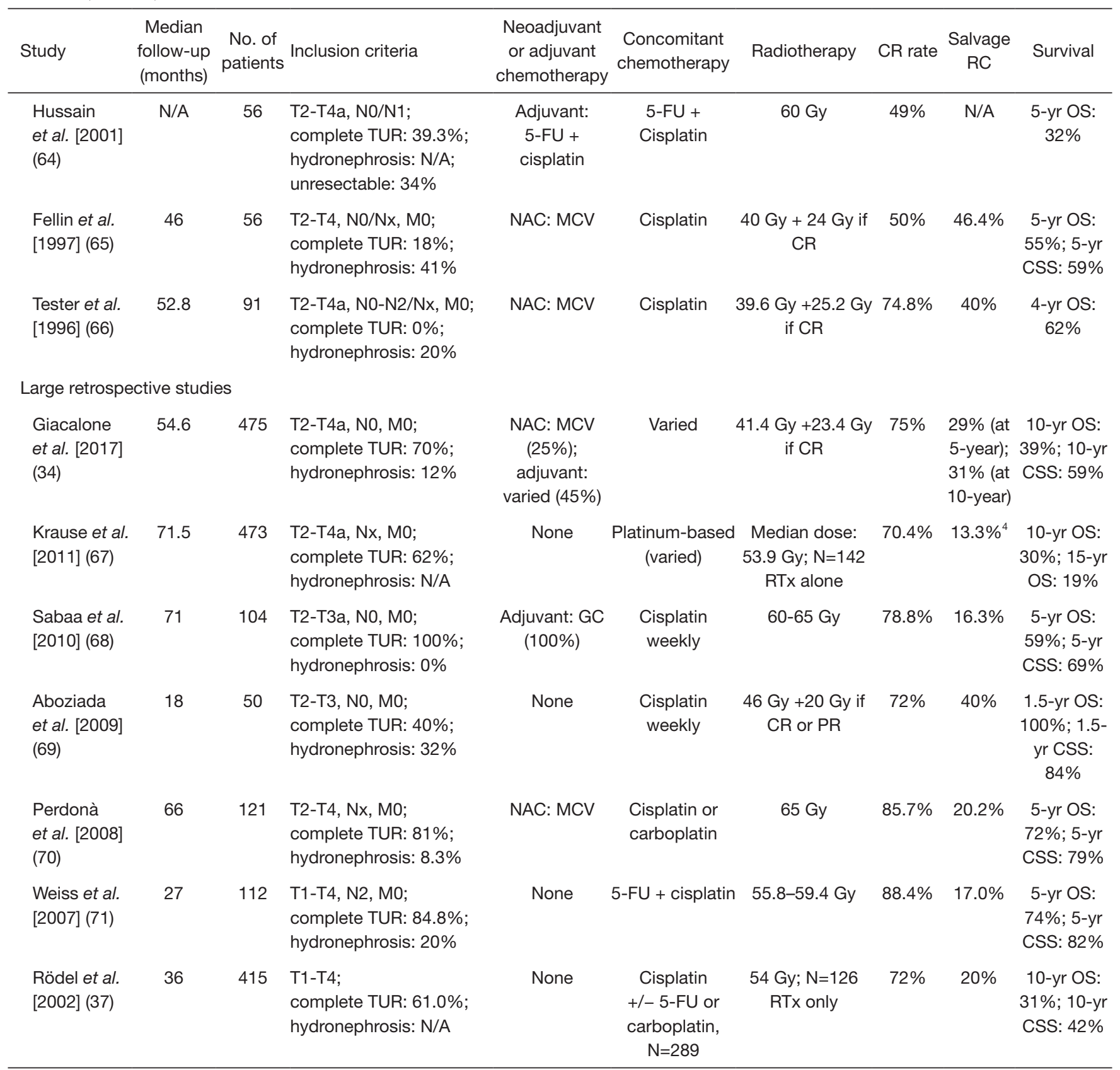

\footnotetext{
${ }^{1}$, excluding 18 patients (33.3\%) who were treated with primary RC after CR to induction treatment; ${ }^{2}$, CR defined as pT0, Ta, Tis on post induction tumor site biopsy; ${ }^{3}$, only $14.3 \%$ of patients with persistent or recurrent invasive tumors underwent salvage RC; the other patients refused surgery for tumor dissemination, locally advanced inoperable tumor or poor performance status; ${ }^{4}$, rate of RC in non-responders. TUR, trans-urethral resection; CR, complete response; RC, radical cystectomy; OS, overall survival; CSS, cancer-specific survival; 5-FU, 5-fluorouracil; N/A, not available; NAC, neoadjuvant chemotherapy; MCV, methotrexate; cisplatin; vinblastine; PR, partial response; GC, gemcitabine + cisplatin; RTx, radiotherapy.
} 
and led to frequent protocol deviations. Conclusions about the non-inferiority of BSP could not be determined as there were too few participants. Unfortunately, it is unlikely that another phase 3 study comparing RC with NAC to TMT will be completed given the adversities encountered in the SPARE trial.

Using the National Cancer Database, two retrospective analysis comparing $\mathrm{RC}$ to $\mathrm{BSP}$ were performed with propensity score matching (PSM) $(74,75)$. The first study included 6,606 patients who underwent RC and 1,773 who received chemoradiation (CRT). CRT was associated with decreased mortality at 1 year (HR 0.84 ) but worse outcomes at 2 and 3 years (HR 1.4 and 1.5, respectively). The 5-year OS rate was $38 \%$ for RC vs. $30 \%$ for CRT. The second study included 22,680 patients who were treated with $\mathrm{RC}$ and 9,620 patients who underwent BSP, $15.5 \%$ being treated with CRT. The reported 5 -year OS for RC was $48 \%$ compared to $30 \%$ for CRT. Most recently, Dafashy et al. used the Surveillance, Epidemiology, and End Results (SEER) Medicare database to compare TMT to RC (76). They included 2,963 patients and performed PSM as well as inverse probability of treatment weighting (IPTW). TMT was associated with a significantly decreased CSS (PSM: HR 1.55, IPTW: HR 1.51) and OS (PSM: HR 1.49, IPTW: HR 1.54) compared to RC.

On the other hand, a recent small retrospective study of 112 patients, who also used a more comprehensive PSM to compare RC to TMT found, with a median follow-up of 4.51 years, no differences between OS and CSS ( $\mathrm{P}=0.63$ and $\mathrm{P}=0.49$, respectively) (77). Median OS was 6.61 years, while 5 -year CSS was $73.2 \%$ and $76.2 \%$ for RC and TMT, respectively. However, similar to the other reports, this study is not devoid of limitations. The institution's usual practice is to re-evaluate patient after NAC: if a significant response is observed, TMT is recommended, whereas patients with a poor response would be recommended RC (78). As $35 \%$ of patients received NAC, this created an important confounding variable that was not accounted for, positively enriching the TMT group with patients having a favorable tumor profile and subsequent outcome. Kim et al. also reported comparable CSS and OS between RC and TMT, with only a decrease in the 5 -year local recurrence free survival in the TMT group (79). Finally, a recent metaanalysis comparing RC to TMT, which included 57 studies and more than 30,000 patients, did not show a statistically significant different 10 -year OS $35.1 \%$ for RC vs. 30.9\% for TMT, $\mathrm{P}=0.32)$ or 10 -year CSS $(50.9 \%$ for TMT vs. $57.8 \%$ for $\mathrm{RC}, \mathrm{P}=0.26$ ) between the two treatment options (21).
Apart from the limitations inherent to retrospective reviews using large data base, even applying sophisticated statistical methods, without an upfront properly performed randomized trial, any comparison between RC and BSP is bound to be limited by patient selection, disease extension incorrectly established by clinical investigations, and other unrecognized confounding variables. All in all, even though conflicting results exist in the literature and large multicentre RCT comparing TMT and RC is lacking, TMT can yield comparable oncological outcomes and similar long-term survival rates when patients are appropriately selected $(3,4)$. Moreover, as recent studies have shown that up to $50 \%$ of patients do not receive any definitive therapy, TMT should be viewed as a complementary rather than competitive option for patients with MIBC (12).

\section{Recurrence}

CR rate post-TMT ranges from 66 to $88 \%$ in the literature, depending on selection criteria $(21,27,34,56)$. Among patients with a CR, $12 \%$ to $43 \%$ will develop a local recurrence. By pooling results of several trials, the RTOG reported a 5- and 10-year rates of muscle-invasive recurrence at $13 \%$ and $14 \%$, respectively, and $31 \%$ and $36 \%$ for nonmuscle-invasive recurrence (NMIBC), respectively (56). Median time to recurrence tends to be less than 2 years, but late recurrences in up to $8 \%$ of patients more than 10 years after CR have been reported (80). Salvage RC is the standard of care for recurrence of MIBC in surgically fit patients. The average rate of salvage $\mathrm{RC}$ reported in the literature ranges from $25 \%$ to $30 \%$, with many studies having less than 5 years of follow-up data (81). However, this rate can be reduced with better patient selection as shown by the Massachusetts General Hospital experience, in which the rate of 5 -year salvage RC decreased from $42 \%$ to $16 \%$ (34). Similarly, Hall et al. reported a 2-year salvage $\mathrm{RC}$ rate of $11 \%$ for the TMT group in a randomized controlled trial setting (39).

Patients with NMIBC (i.e., Tis, Ta and T1) recurrences can be managed by conservative management (TURBT +/intravesical BCG) $(80,82)$. Zietman et al. initially reported on the Boston experience among patients who developed NMIBC recurrences after CR (82). With updated followup and more patients, they recently observed a worse 10year CSS for patients with NMIBC recurrence compared with those without $(72.1 \%$ vs. $78.4 \%, \mathrm{P}=0.002$, respectively), but similar OS (43.6\% vs. 54.1\%, $\mathrm{P}=0.66$, respectively) (80). 
Reported rate of salvage $\mathrm{RC}$ in the literature for patients with NMIBC recurrence after CR, which are initially managed by TURBT +/- BCG, is around $25-30 \%(80,82-84)$.

It is important to note that only 10 patients with $\mathrm{T} 1$ recurrences were managed conservatively in the previously cited studies. As such, until more data is available, it may be more prudent to offer salvage RC in surgical candidates with $\mathrm{T} 1$ recurrences.

\section{Salvage $R C$}

Salvage RC is recommended for patients that do not achieve a CR (i.e., non-responders or partial responders) or develop subsequent invasive recurrences after CR following TMT. The overall 5- and 10-year CSS rates for patients undergoing salvage RC in both settings (non-responders and for recurrent tumor) are approximately $50-60 \%$ and $40-50 \%$, respectively $(17,34,37,56)$. Reported 5 -year and 10 -year OS rates are approximately $45 \%$ and $20-30 \%$, respectively $(17,56)$. From the limited available data, there appears to be no significant reduction in OS related to delay in cystectomy after TMT for MIBC relapse.

Recent contemporary series comparing salvage $\mathrm{RC}$ to primary $\mathrm{RC}$ suggest no significant differences in perioperative mortality and major complications rates, with a slight increase in minor complications rate $(17,85,86)$. Interestingly, Eswara et al. compared immediate salvage RC (for non-responder, performed after split course assessment) or delayed salvage RC (for MIBC recurrence) (17). Immediate salvage RC had significantly more cardiovascular and hematological complications (i.e., deep vein thrombosis, pulmonary embolism, transfusion, myocardial infarction), while delayed cystectomies had significantly more tissue healing complications (wound infection, fascial dehiscence, ureteral and anastomotic stricture). Moreover, better CSS was seen in the delayed salvage RC group; this difference may be explained by the fact that tumor who initially failed to respond to TMT may have a more aggressive biology and occult distant metastasis.

Nevertheless, appropriate patient counselling about salvage RC is important. Indeed, previous pelvic radiotherapy treatment limits the ability to perform nerve sparing surgery as well as the choice of urinary diversions. Orthotopic neobladder reconstruction, although technically feasible, will be associated with an increased risk of functional complications (such as radiationinduced impaired bowel healing, anastomotic stricture and incontinence) and is not recommended.

\section{Follow-up post TMT}

As previously highlighted, since the majority of local recurrences are in the bladder and can occur even 10 years post TMT, long-term regular cystoscopy and imaging is mandated. Multiple follow-up protocols exist and most commonly recommend cystoscopy with urine cytology every 3-4 months during the first year, every 4-6 months in the second year, and every $6-12$ months afterwards $(56,87)$. The AUA guidelines recommend cross-sectional imaging of the chest, abdomen and pelvis every 6 months for the first 2 years, and then annually (4).

All the RTOG trials always included post-treatment biopsy and exam under anesthesia to assess response (56). Despite the absence of high level-evidence supporting routine biopsy in the absence of visibly detected tumor on cystoscopy or imaging, we suggest to perform systematic resection of the previous scar in surgical candidates as it is not uncommon for the tumor to re-grow underneath a normal appearing resection scar.

\section{$Q O L$}

Even though a goal of TMT is to maintain QOL by avoiding $\mathrm{RC}$-associated morbidities, no studies so far prospectively assessed QOL between the two options. Only one retrospective study compared long-term QOL post TMT versus RC; however, no baseline data were available (88). With a median follow-up of 5.6 years, the authors reported a better general QOL for TMT $(\mathrm{P}=0.001)$. Patients undergoing TMT also had higher physical, occupational and social role functioning, better emotional and cognitive functioning, better bowel function, fewer bowel symptoms, better sexual function and better body image. However, urinary symptom scores were similar. Pooled analysis from the RTOG prospective trials confirmed that late toxicities were acceptable after TMT: $6 \%$ experienced grade 3 genitourinary toxicity, $2 \%$ grade 3-4 gastrointestinal toxicity, and $<1 \%$ of patients required cystectomy for treatment-related effects (89). Using the RTOG criteria, the BC2001 trial reported a grade 3/4 genitourinary toxicity rate of $3.8 \%$ at 2 years (47). The overall cumulative grade $3 / 4$ toxicity was $13 \%$ at 2 years. Salvage cystectomy was performed in $0.9 \%$ of patients due to radiation therapy side effects. Studies reporting acute and chronic toxicity from TMT are reviewed in Table 3.

Finally, a small urodynamic study done on 32 longterm survivors post TMT showed that $75 \%$ of patients 


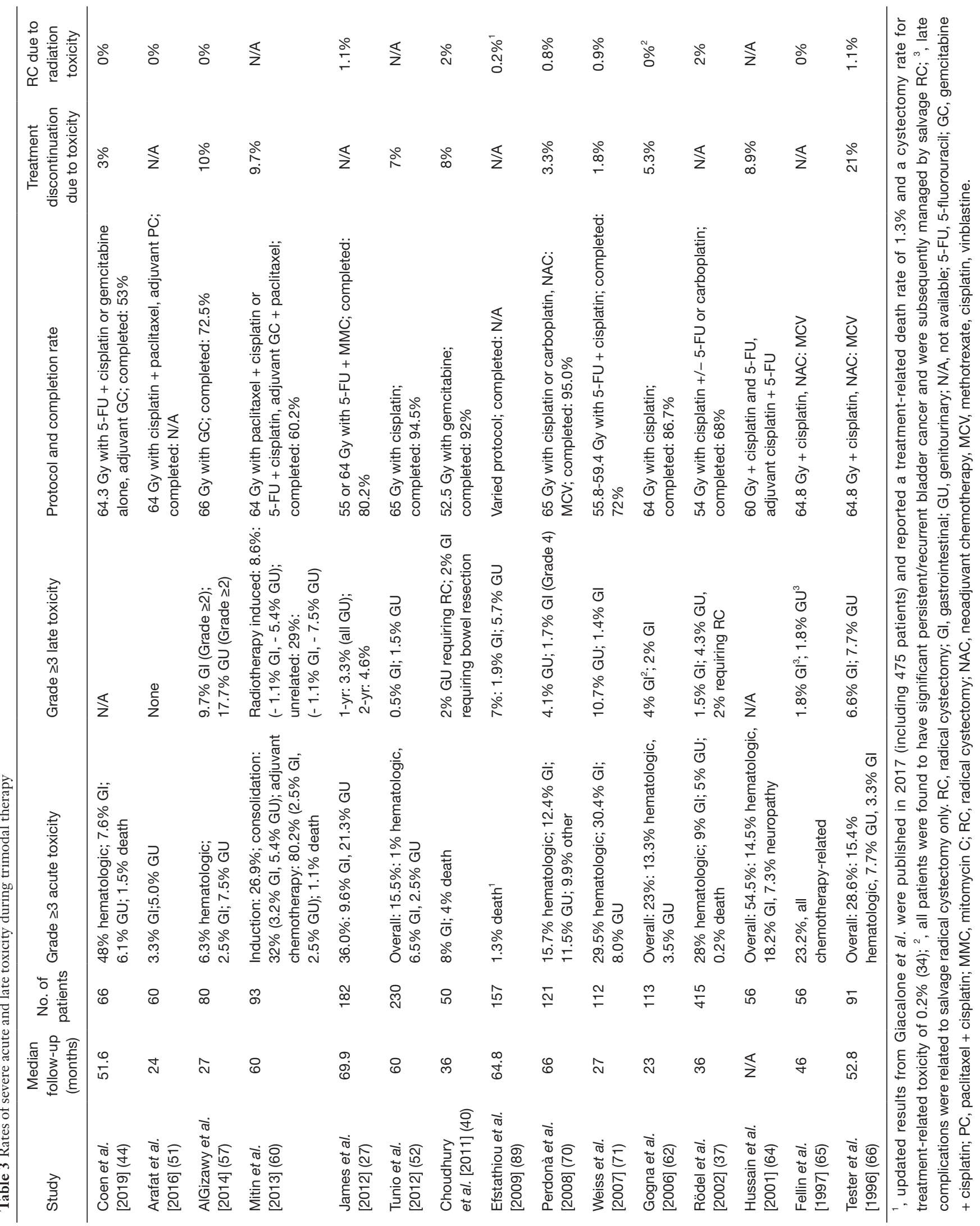


had a normal functioning bladder, with most other patients experiencing decreased bladder compliance (90); $36 \%$ of men had normal erections and another $18 \%$ had weaker erections but sufficient for intercourse. One ongoing trial looking to prospectively assess the QOL of patients after BSP will shed light on the subject by limiting existing limitations of retrospective design and interpretation biases (NCT02688348).

Overall, TMT is well tolerated. Long-term requirement for cystoscopy and follow-up as well as the acceptance to forgo a neobladder reconstruction in the event that a patient needs salvage $\mathrm{RC}$ is important to consider when counselling patients about this treatment option.

\section{Cost of TMT}

Williams et al. recently published on the comparison of costs of RC and TMT (91). Using the SEER Medicare database, they showed that median cost was higher for TMT at 90 days ( $\$ 83,754$ vs. $\$ 686,892), 180$ days $(\$ 187,162$ vs. $\$ 109,078)$ and 365 days $(\$ 289,142$ vs. $\$ 148,757)$. When performing inverse probability of treatment-weighted propensity score models analyses, TMT was associated with a median increased cost of $\$ 136,935$ at 1 year after diagnosis. Outpatient care, radiology, medication expenses and pathology/laboratory costs contributed to the higher costs associated with TMT. No data on QOL was reported. Extrapolating these cost figures to a similar group of patients in 2017 would result in excess spending of $\$ 468$ million with TMT. However, the review involved a longer time span (2002 to 2011), limited data were available on the quality of the radiotherapy and the cost of the management of potential associated medical comorbidities, likely to be significantly more present in TMT patients, were not taken into consideration in the final cost calculation.

\section{Neoadjuvant and adjuvant chemotherapy in TMT}

Extrapolation from the surgical literature, where neoadjuvant cisplatin-based chemotherapy shows improvement in OS, led to the interest of studying neoadjuvant and adjuvant chemotherapy when using BSP and TMT in particular. However, there is no clear data supporting its role and its use remains controversial. The Medical Research Council showed in an international phase III trial that neoadjuvant cisplatin, methotrexate and vinblastine for patients treated with cystectomy and/ or radiotherapy increased 10 -year OS from $30 \%$ to $36 \%$, with a statistically significant $16 \%$ reduction in the risk of death (92). However, patients in the bladder-sparing group only received radiotherapy alone, and not TMT. On the other hand, randomized trials in head and neck and cervical cancer showed decreased survival with NAC followed by radiotherapy compared to radiotherapy alone, which challenges if extrapolation from surgical literature can confidently be applied $(93,94)$.

The RTOG 89-03 compared neoadjuvant cisplatin, methotrexate and vinblastine with concurrent chemoradiotherapy to only concurrent chemoradiotherapy (58). There were no significant differences in OS or distant metastases, but there were more treatment-related deaths in the arm receiving NAC, highlighting the risks associated with systemic chemotherapy. Moreover, only two-thirds of patients completed their treatment per protocol due to poor tolerability. Similar results were reported in the recent metaanalysis comparing NAC with TMT vs. TMT alone (21). Nevertheless, all the published studies comparing these regimens have been underpowered and potentially used suboptimal regimens (such as 2 cycles of systemic chemotherapy instead of 4).

As for adjuvant chemotherapy, no survival data from phase 3 trials have been published in the TMT setting. Phase 1 and 2 studies looking at adjuvant chemotherapy after TMT report a lower tolerability and completion rate, with only $45-70 \%$ of patients completed treatment per protocol $(33,95)$. Severe toxicity (grade 3 or 4 ) also seemed to be more common than in the neoadjuvant setting.

To conclude, although there exists clinical rationale to use neoadjuvant or adjuvant chemotherapy with TMT, welldesigned large RCTs are required to elucidate their role with TMT. Appropriate counselling to patients regarding probable higher toxicity rate is advised if such therapy is considered.

\section{Predictive markers of response to TMT}

Biomarkers were developed with the hope to be able to prognosticate and predict response to therapy in order to best guide treatment options for patients with MIBC. Multiple biomarkers have currently been studied in the context of BSP for MIBC (96). MRE-11, a DNA-damage signaling protein, is the only biomarker that was shown in multiple studies to be a predictive factor associated with survival following radiotherapy for bladder cancer (97-99). Low tumor MRE11 expression was associated with worse CSS compared to high expression. However, manual MRE11 
scoring was not validated across centers and later failed to show significant differences in CSS (100). Better staining methodology with automated digital scoring needs to be developed for MRE-11 to become a robust and reproducible biomarker for radiotherapy success in MIBC. Yang et al. developed a 24-gene hypoxia signature and reported a prognostic and predictive value for local relapse-free survival for patients receiving radiotherapy and predicted a benefit from the addition of the carbogen and nicotinamide (hypoxia modification) to radiotherapy (101). However, no studies have currently evaluated chemoradiation therapy with hypoxia modification.

Transcription profiling is also emerging as a potential tool to guide patient selection and treatment choice. A recently published study, examining gene expression profiling of patients treated with TMT or NAC plus RC, reported that higher immune infiltration and higher IFNgamma gene expression were association with a significantly improved CSS after TMT (102). In comparison, higher stromal gene expression was associated with a significantly worse CSS and OS in the NAC plus RC cohort.

Song et al. highlighted the potential for personalized treatment in patients with MIBC (103). They developed a putative algorithm where patients with high expression of a predictive biomarker for TMT would be offered TMT, while patients with low expression of the biomarker would be offered RC. Nevertheless, even though promising results have been reported with molecular biomarkers, none are routinely used in the clinical setting and prospective clinical trials are required to validate these findings before their implementation in clinical practice.

\section{Tetramodal bladder-preservation therapy}

One Japanese center has published on a BSP where partial cystectomy is added to TMT. The goal is to overcome the following limitations of TMT: subclinical residual disease in the original MIBC site and the lack of regional lymph nodes resection. Their protocol consists of debulking TURBT followed by 40 Gy of irradiation with concomitant cisplatin. Patients with solitary MIBC with no involvement of bladder neck or trigone and no residual disease (or minimal NMIBC disease) after chemoradiation were offered consolidative partial cystectomy with pelvic lymph node dissection (104). Recently, Kijima et al. published on their updated results on 107 patients with 5-year OS and CSS rates were 93\% and $91 \%$, respectively (105); $9 \%$ of patients had residual muscle-invasive disease and $2 \%$ had lymph node metastasis on pathology, while $18 \%$ of patients experienced local recurrence, including 4\% with MIBC. They also reported favorable bladder function with satisfactory bladder capacity and QOL based on SF-36 scores. Nevertheless, this approach is still considered experimental and further studies are required to investigate and evaluate reproducibility of these results.

\section{Current and future directions}

Recent development of immune checkpoint inhibitors targeting programmed death-1 (PD-1) and programmeddeath ligand-1 (PDL-1) showed improved survival in the $2^{\text {nd }}$ line setting of metastatic urothelial carcinoma after cisplatin-based chemotherapy and were also approved in 1st line for patients unfit for cisplatin chemotherapy. There is a biologic rational in combining immunotherapy with current BSP. Our recent preclinical findings support the combination of immunotherapy and BSP in achieving maximal tumor inhibition and potentiating abscopal antitumor effects (106). This idea is highly promising given recent data from a phase III trial comparing durvalumab after definite chemoradiotherapy to chemoradiotherapy alone for locally advanced non-small-cell lung cancer, showing significantly longer OS and progression-free survival for the immunotherapy arm (107). Multiple phase I to III trials using immune checkpoint inhibitors as neoadjuvant or adjuvant therapy in combination to radiotherapy or TMT for patients with bladder cancer have currently been approved and are ongoing (NCT03768570, NCT03171025, NCT03171025, NCT03491930, NCT02621151, NCT03747419, NCT03775265, NCT03617913).

We foresee a significant increasing use of TMT in the management of MIBC. Optimization of chemoradiotherapy and BSP is still an ongoing goal and controversies remain. Areas of further research includes: (I) the role of pelvic nodal radiation on outcomes, (II) the costeffectiveness of TMT, (III) the role of neoadjuvant and adjuvant chemotherapy, (IV) the impact of immunotherapy (neoadjuvant, concurrent or adjuvant), (V) the management of T1 recurrences after TMT, and (VI) the prospective validation of predictive biomarkers to guide therapy for MIBC patients, and its implementation in clinical practice.

\section{Conclusions}

BSP and most specifically TMT with prompt salvage RC 
has been shown to give oncological outcomes comparable to upfront RC, with an improvement in QOL. It can therefore be considered as an attractive alternative to $\mathrm{RC}$ in appropriately selected patients or surgically unfit patients. Appropriate patient counselling and multi-disciplinary approach is of paramount importance for successful results. Identification and prospective validation of novel predictive biomarkers are needed to help us better guide therapy and look promising to improve current oncological outcomes in BSP.

\section{Acknowledgments}

Funding: None.

\section{Footnote}

Provenance and Peer Review: This article was commissioned by the Guest Editors (Ja Hyeon Ku, Ho Kyung Seo, Seok Ho Kang) for the series "Muscle-Invasive Bladder Cancer" published in Translational Andrology and Urology. The article has undergone external peer review.

Conflicts of Interest: All authors have completed the ICMJE uniform disclosure form (available at http://dx.doi. org/10.21037/tau.2020.02.10). The series "Muscle-Invasive Bladder Cancer" was commissioned by the editorial office without any funding or sponsorship. Dr. Souhami reports other from Varian Medical Systems, other from Janssen, other from AbbVie, outside the submitted work. The authors have no other conflicts of interest to declare.

Ethical Statement: The authors are accountable for all aspects of the work in ensuring that questions related to the accuracy or integrity of any part of the work are appropriately investigated and resolved.

Open Access Statement: This is an Open Access article distributed in accordance with the Creative Commons Attribution-NonCommercial-NoDerivs 4.0 International License (CC BY-NC-ND 4.0), which permits the noncommercial replication and distribution of the article with the strict proviso that no changes or edits are made and the original work is properly cited (including links to both the formal publication through the relevant DOI and the license). See: https://creativecommons.org/licenses/by-nc-nd/4.0/.

\section{References}

1. Bray F, Ferlay J, Soerjomataram I, et al. Global cancer statistics 2018: GLOBOCAN estimates of incidence and mortality worldwide for 36 cancers in 185 countries. CA Cancer J Clin 2018;68:394-424.

2. Burger M, Catto JW, Dalbagni G, et al. Epidemiology and risk factors of urothelial bladder cancer. Eur Urol 2013;63:234-41.

3. Alfred Witjes J, Lebret T, Comperat EM, et al. Updated 2016 EAU Guidelines on Muscle-invasive and Metastatic Bladder Cancer. Eur Urol 2017;71:462-75.

4. Chang SS, Bochner BH, Chou R, et al. Treatment of NonMetastatic Muscle-Invasive Bladder Cancer: AUA/ASCO/ ASTRO/SUO Guideline. J Urol 2017;198:552-9.

5. Kulkarni GS, Black PC, Sridhar SS, et al. Canadian Urological Association guideline: Muscle-invasive bladder cancer. Can Urol Assoc J 2019:230-8.

6. Howlader N, Noone AM, Krapcho M, et al. SEER Cancer Statistics Review, 1975-2014, National Cancer Institute. Bethesda, MD. Available online: https://seer.cancer.gov/ csr/1975_2014/, based on November 2016 SEER data submission, posted to the SEER web site, April 2017.

7. Quek ML, Stein JP, Daneshmand S, et al. A critical analysis of perioperative mortality from radical cystectomy. J Urol 2006;175:886-9; discussion 889-90.

8. Bream MJ, Maurice MJ, Altschuler J, et al. Increased Use of Cystectomy in Patients 75 and Older: A Contemporary Analysis of Survival and Perioperative Outcomes From the National Cancer Database. Urology 2017;100:72-8.

9. Isbarn $\mathrm{H}$, Jeldres $\mathrm{C}$, Zini L, et al. A population based assessment of perioperative mortality after cystectomy for bladder cancer. J Urol 2009;182:70-7.

10. Schiffmann J, Gandaglia G, Larcher A, et al. Contemporary 90 -day mortality rates after radical cystectomy in the elderly. Eur J Surg Oncol 2014;40:1738-45.

11. Hounsome LS, Verne J, McGrath JS, et al. Trends in operative caseload and mortality rates after radical cystectomy for bladder cancer in England for 1998-2010. Eur Urol 2015;67:1056-62.

12. Gore JL, Litwin MS, Lai J, et al. Use of radical cystectomy for patients with invasive bladder cancer. J Natl Cancer Inst 2010;102:802-11.

13. Solsona E, Iborra I, Collado A, et al. Feasibility of radical transurethral resection as monotherapy for selected patients with muscle invasive bladder cancer. J Urol 2010;184:475-80. 
14. Herr HW. Transurethral resection of muscle-invasive bladder cancer: 10-year outcome. J Clin Oncol 2001;19:89-93.

15. Capitanio U, Isbarn H, Shariat SF, et al. Partial cystectomy does not undermine cancer control in appropriately selected patients with urothelial carcinoma of the bladder: a population-based matched analysist. Urology 2009;74:858-64.

16. Kassouf W, Swanson D, Kamat AM, et al. Partial cystectomy for muscle invasive urothelial carcinoma of the bladder: a contemporary review of the M. D. Anderson Cancer Center experience. J Urol 2006;175:2058-62.

17. Eswara JR, Efstathiou JA, Heney NM, et al. Complications and long-term results of salvage cystectomy after failed bladder sparing therapy for muscle invasive bladder cancer. J Urol 2012;187:463-8.

18. Smelser WW, Austenfeld MA, Holzbeierlein JM, et al. Where are we with bladder preservation for muscle-invasive bladder cancer in 2017? Indian J Urol 2017;33:111-7.

19. Neoadjuvant cisplatin, methotrexate, and vinblastine chemotherapy for muscle-invasive bladder cancer: a randomised controlled trial. International collaboration of trialists. Lancet 1999;354:533-40.

20. Grossman HB, Natale RB, Tangen CM, et al. Neoadjuvant chemotherapy plus cystectomy compared with cystectomy alone for locally advanced bladder cancer. $\mathrm{N}$ Engl J Med 2003;349:859-66.

21. Fahmy O, Khairul-Asri MG, Schubert T, et al. A systematic review and meta-analysis on the oncological long-term outcomes after trimodality therapy and radical cystectomy with or without neoadjuvant chemotherapy for muscle-invasive bladder cancer. Urol Oncol 2018;36:43-53.

22. Herr HW. Outcome of patients who refuse cystectomy after receiving neoadjuvant chemotherapy for muscleinvasive bladder cancer. Eur Urol 2008;54:126-32.

23. Solsona E, Climent MA, Iborra I, et al. Bladder preservation in selected patients with muscle-invasive bladder cancer by complete transurethral resection of the bladder plus systemic chemotherapy: long-term follow-up of a phase 2 nonrandomized comparative trial with radical cystectomy. Eur Urol 2009;55:911-9.

24. Mazza P, Moran GW, Li G, et al. Conservative Management Following Complete Clinical Response to Neoadjuvant Chemotherapy of Muscle Invasive Bladder Cancer: Contemporary Outcomes of a Multi-Institutional Cohort Study. J Urol 2018;200:1005-13.
25. Herr HW. Editorial Comment on: Bladder Preservation in Selected Patients with Muscle-Invasive Bladder Cancer by Complete Transurethral Resection of the Bladder Plus Systemic Chemotherapy: Long-Term Follow-up of a Phase 2 Nonrandomized Comparative Trial with Radical Cystectomy. Eur Urol 2009;55:920-1.

26. Milosevic M, Gospodarowicz M, Zietman A, et al. Radiotherapy for bladder cancer. Urology 2007;69:80-92.

27. James ND, Hussain SA, Hall E, et al. Radiotherapy with or without chemotherapy in muscle-invasive bladder cancer. N Engl J Med 2012;366:1477-88.

28. Søndergaard J, Holmberg M, Jakobsen AR, et al. A comparison of morbidity following conformal versus intensity-modulated radiotherapy for urinary bladder cancer. Acta Oncol 2014;53:1321-8.

29. Turgeon GA, Souhami L, Cury FL, et al. Hypofractionated intensity modulated radiation therapy in combined modality treatment for bladder preservation in elderly patients with invasive bladder cancer. Int J Radiat Oncol Biol Phys 2014;88:326-31.

30. Korpics MC, Block AM, Martin B, et al. Concurrent chemotherapy is associated with improved survival in elderly patients with bladder cancer undergoing radiotherapy. Cancer 2017;123:3524-31.

31. Shelley MD, Barber J, Wilt T, et al. Surgery versus radiotherapy for muscle invasive bladder cancer. Cochrane Database Syst Rev 2002(1):CD002079.

32. Kaufman DS, Winter KA, Shipley WU, et al. The initial results in muscle-invading bladder cancer of RTOG 95-06: phase I/II trial of transurethral surgery plus radiation therapy with concurrent cisplatin and 5 -fluorouracil followed by selective bladder preservation or cystectomy depending on the initial response. Oncologist 2000;5:471-6.

33. Kaufman DS, Winter KA, Shipley WU, et al. Phase I-II RTOG study (99-06) of patients with muscleinvasive bladder cancer undergoing transurethral surgery, paclitaxel, cisplatin, and twice-daily radiotherapy followed by selective bladder preservation or radical cystectomy and adjuvant chemotherapy. Urology 2009;73:833-7.

34. Giacalone NJ, Shipley WU, Clayman RH, et al. Longterm Outcomes After Bladder-preserving Tri-modality Therapy for Patients with Muscle-invasive Bladder Cancer: An Updated Analysis of the Massachusetts General Hospital Experience. Eur Urol 2017;71:952-60.

35. Pauwels B. Combined Modality Therapy of Gemcitabine and Radiation. The Oncologist 2005;10:34-51.

36. Coppin CM, Gospodarowicz MK, James K, et al. 
Improved local control of invasive bladder cancer by concurrent cisplatin and preoperative or definitive radiation. The National Cancer Institute of Canada Clinical Trials Group. J Clin Oncol 1996;14:2901-7.

37. Rödel C, Grabenbauer GG, Kühn R, et al. CombinedModality Treatment and Selective Organ Preservation in Invasive Bladder Cancer: Long-Term Results. J Clin Oncol 2002;20:3061-71.

38. Chung DE, Wysock JS, Lee RK, et al. Outcomes and complications after $532 \mathrm{~nm}$ laser prostatectomy in anticoagulated patients with benign prostatic hyperplasia. J Urol 2011;186:977-81.

39. Hall E, Hussain SA, Porta N, et al. BC2001 longterm outcomes: A phase III randomized trial of chemoradiotherapy versus radiotherapy (RT) alone and standard RT versus reduced high-dose volume RT in muscle-invasive bladder cancer. J Clin Oncol 2017;35:280.

40. Choudhury A, Swindell R, Logue JP, et al. Phase II study of conformal hypofractionated radiotherapy with concurrent gemcitabine in muscle-invasive bladder cancer. J Clin Oncol 2011;29:733-8.

41. Hoskin PJ, Rojas AM, Bentzen SM, et al. Radiotherapy with concurrent carbogen and nicotinamide in bladder carcinoma. J Clin Oncol 2010;28:4912-8.

42. Galsky MD, Hahn NM, Rosenberg JE, et al. Defining "cisplatin ineligible" patients with metastatic bladder cancer. J Clin Oncol 2011;29:238.

43. Leow JJ, Bedke J, Chamie K, et al. SIU-ICUD consultation on bladder cancer: treatment of muscleinvasive bladder cancer. World J Urol 2019;37:61-83.

44. Coen JJ, Zhang P, Saylor PJ, et al. Bladder Preservation With Twice-a-Day Radiation Plus Fluorouracil/Cisplatin or Once Daily Radiation Plus Gemcitabine for MuscleInvasive Bladder Cancer: NRG/RTOG 0712-A Randomized Phase II Trial. J Clin Oncol 2019;37:44-51.

45. Kang JJ, Steinberg ML, Kupelian P, et al. Whole Versus Partial Bladder Radiation: Use of an Image-guided Hypofractionated IMRT Bladder-preservation Protocol. Am J Clin Oncol 2018;41:107-14.

46. Cowan RA, McBain CA, Ryder WD, et al. Radiotherapy for muscle-invasive carcinoma of the bladder: results of a randomized trial comparing conventional whole bladder with dose-escalated partial bladder radiotherapy. Int J Radiat Oncol Biol Phys 2004;59:197-207.

47. Huddart RA, Hall E, Hussain SA, et al. Randomized noninferiority trial of reduced high-dose volume versus standard volume radiation therapy for muscleinvasive bladder cancer: results of the BC2001 trial
(CRUK/01/004). Int J Radiat Oncol Biol Phys

2013;87:261-9.

48. Goldsmith B, Baumann BC, He J, et al. Occult Pelvic Lymph Node Involvement in Bladder Cancer: Implications for Definitive Radiation. Int J Radiat Oncol Biol Phys 2014;88:603-10.

49. Stein JP, Lieskovsky G, Cote R, et al. Radical cystectomy in the treatment of invasive bladder cancer: long-term results in 1,054 patients. J Clin Oncol 2001;19:666-75.

50. Yafi FA, Aprikian AG, Chin JL, et al. Contemporary outcomes of 2287 patients with bladder cancer who were treated with radical cystectomy: a Canadian multicentre experience. BJU Int 2011;108:539-45.

51. Arafat W, Darwish A, Naoum GE, et al. Comparison between standard and reduced volume radiotherapy in bladder preservation trimodality protocol for muscleinvasive bladder cancer patients. Ecancermedicalscience 2016;10:682.

52. Tunio MA, Hashmi A, Qayyum A, et al. Whole-Pelvis or Bladder-Only Chemoradiation for Lymph Node-Negative Invasive Bladder Cancer: Single-Institution Experience. Int J Radiat Oncol Biol Phys 2012;82:e457-62.

53. Moonen L, vd Voet H, de Nijs R, et al. Muscle-invasive bladder cancer treated with external beam radiotherapy: pretreatment prognostic factors and the predictive value of cystoscopic re-evaluation during treatment. Radiother Oncol 1998;49:149-55.

54. Tran E, Souhami L, Tanguay S, et al. Bladder conservation treatment in the elderly population: results and prognostic factors of muscle-invasive bladder cancer. Am J Clin Oncol 2009;32:333-7.

55. Ploussard G, de la Taille A, Moulin M, et al. Comparisons of the perioperative, functional, and oncologic outcomes after robot-assisted versus pure extraperitoneal laparoscopic radical prostatectomy. Eur Urol 2014;65:610-9.

56. Mak RH, Hunt D, Shipley WU, et al. Long-term outcomes in patients with muscle-invasive bladder cancer after selective bladder-preserving combined-modality therapy: a pooled analysis of Radiation Therapy Oncology Group protocols 8802, 8903, 9506, 9706, 9906, and 0233. J Clin Oncol 2014;32:3801-9.

57. AlGizawy SM, Essa HH, Abdel-Wanis ME, et al. Trimodality bladder-sparing approach versus radical cystectomy for invasive bladder cancer. J Radiother Pract 2014;13:428-37.

58. Shipley WU, Winter KA, Kaufman DS, et al. Phase III trial of neoadjuvant chemotherapy in patients with invasive 
bladder cancer treated with selective bladder preservation by combined radiation therapy and chemotherapy: initial results of Radiation Therapy Oncology Group 89-03. J Clin Oncol 1998;16:3576-83.

59. Housset M, Maulard C, Chretien Y, et al. Combined radiation and chemotherapy for invasive transitional-cell carcinoma of the bladder: a prospective study. J Clin Oncol 1993;11:2150-7.

60. Mitin T, Hunt D, Shipley WU, et al. Transurethral surgery and twice-daily radiation plus paclitaxel-cisplatin or fluorouracil-cisplatin with selective bladder preservation and adjuvant chemotherapy for patients with muscle invasive bladder cancer (RTOG 0233): a randomised multicentre phase 2 trial. Lancet Oncol 2013;14:863-72.

61. Lagrange JL, Bascoul-Mollevi C, Geoffrois L, et al. Quality of Life Assessment After Concurrent Chemoradiation for Invasive Bladder Cancer: Results of a Multicenter Prospective Study (GETUG 97-015). Int J Radiat Oncol Biol Phys 2011;79:172-8.

62. Gogna NK, Matthews JHL, Turner SL, et al. Efficacy and tolerability of concurrent weekly low dose cisplatin during radiation treatment of localised muscle invasive bladder transitional cell carcinoma: A report of two sequential Phase II studies from the Trans Tasman Radiation Oncology Group. Radiother Oncol 2006;81:9-17.

63. Kragelj B, Zaletelkragelj L, Sedmak B, et al. Phase II study of radiochemotherapy with vinblastine in invasive bladder cancer. Radiother Oncol 2005;75:44-7.

64. Hussain MHA, Glass TR, Forman J, et al. Combination Cisplatin, 5-Fluorouracil and Radiation Therapy for Locally Advanced Unresectable or Medically Unfit Bladder Cancer Cases: A Southwest Oncology Group Study. J Urol 2001;165:56-60; discussion 60-1.

65. Fellin G, Graffer U, Bolner A, et al. Combined chemotherapy and radiation with selective organ preservation for muscle-invasive bladder carcinoma. A single-institution phase II study. Br J Urol 1997;80:44-9.

66. Tester W, Caplan R, Heaney J, et al. Neoadjuvant combined modality program with selective organ preservation for invasive bladder cancer: results of Radiation Therapy Oncology Group phase II trial 8802. J Clin Oncol 1996;14:119-26.

67. Krause FS, Walter B, Ott OJ, et al. 15-year survival rates after transurethral resection and radiochemotherapy or radiation in bladder cancer treatment. Anticancer Res 2011;31:985-90.

68. Sabaa MA, El-Gamal OM, Abo-Elenen M, et al. Combined modality treatment with bladder preservation for muscle invasive bladder cancer. Urol Oncol 2010;28:14-20.

69. Aboziada MA, Hamza HM, Abdlrahem AM. Initial results of bladder preserving approach by chemo-radiotherapy in patients with muscle invading transitional cell carcinoma. J Egypt Natl Canc Inst 2009;21:167-74.

70. Perdonà S, Autorino R, Damiano R, et al. Bladder-sparing, combined-modality approach for muscle-invasive bladder cancer: a multi-institutional, long-term experience. Cancer 2008;112:75-83.

71. Weiss C, Engehausen DG, Krause FS, et al. Radiochemotherapy With Cisplatin and 5-Fluorouracil After Transurethral Surgery in Patients With Bladder Cancer. Int J Radiat Oncol Biol Phys 2007;68:1072-80.

72. Culp SH, Dickstein RJ, Grossman HB, et al. Refining patient selection for neoadjuvant chemotherapy before radical cystectomy. J Urol 2014;191:40-7.

73. Huddart RA, Birtle A, Maynard L, et al. Clinical and patient-reported outcomes of SPARE - a randomised feasibility study of selective bladder preservation versus radical cystectomy. BJU Int 2017;120:639-50.

74. Ritch CR, Balise R, Prakash NS, et al. Propensity matched comparative analysis of survival following chemoradiation or radical cystectomy for muscle-invasive bladder cancer. BJU Int 2018;121:745-51.

75. Cahn DB, Handorf EA, Ghiraldi EM, et al. Contemporary use trends and survival outcomes in patients undergoing radical cystectomy or bladder-preservation therapy for muscle-invasive bladder cancer. Cancer 2017;123:4337-45.

76. Dafashy T, Phillips D, Shan Y, et al. Population-based outcomes comparing radical cystectomy with trimodal therapy for patients diagnosed with localized muscleinvasive bladder cancer. J Clin Oncol 2019;37:e16029.

77. Kulkarni GS, Hermanns T, Wei Y, et al. Propensity Score Analysis of Radical Cystectomy Versus BladderSparing Trimodal Therapy in the Setting of a Multidisciplinary Bladder Cancer Clinic. J Clin Oncol 2017;35:2299-305.

78. El-Achkar A, Kassouf W. Re: Propensity Score Analysis of Radical Cystectomy Versus Bladder-sparing Trimodal Therapy in the Setting of a Multidisciplinary Bladder Cancer Clinic. Eur Urol 2018;73:810-1.

79. Kim YJ, Byun SJ, Ahn H, et al. Comparison of outcomes between trimodal therapy and radical cystectomy in muscle-invasive bladder cancer: a propensity score matching analysis. Oncotarget 2017;8:68996-9004.

80. Sanchez A, Wszolek MF, Niemierko A, et al. Incidence, Clinicopathological Risk Factors, Management and 
Outcomes of Nonmuscle Invasive Recurrence after Complete Response to Trimodality Therapy for Muscle Invasive Bladder Cancer. J Urol 2018;199:407-15.

81. Ploussard G, Daneshmand S, Efstathiou JA, et al. Critical analysis of bladder sparing with trimodal therapy in muscle-invasive bladder cancer: a systematic review. Eur Urol 2014;66:120-37.

82. Zietman AL, Grocela J, Zehr E, et al. Selective bladder conservation using transurethral resection, chemotherapy, and radiation: management and consequences of $\mathrm{Ta}, \mathrm{T} 1$, and Tis recurrence within the retained bladder. Urology 2001;58:380-5.

83. Shipley WU, Kaufman DS, Zehr E, et al. Selective bladder preservation by combined modality protocol treatment: long-term outcomes of 190 patients with invasive bladder cancer. Urology 2002;60:62-7; discussion 67-8.

84. Danesi DT, Arcangeli G, Cruciani E, et al. Conservative treatment of invasive bladder carcinoma by transurethral resection, protracted intravenous infusion chemotherapy, and hyperfractionated radiotherapy: long term results. Cancer 2004;101:2540-8.

85. Iwai A, Koga F, Fujii Y, et al. Perioperative complications of radical cystectomy after induction chemoradiotherapy in bladder-sparing protocol against muscle-invasive bladder cancer: a single institutional retrospective comparative study with primary radical cystectomy. Jpn J Clin Oncol 2011;41:1373-9.

86. Ramani VA, Maddineni SB, Grey BR, et al. Differential complication rates following radical cystectomy in the irradiated and nonirradiated pelvis. Eur Urol 2010;57:1058-63.

87. Efstathiou JA, Spiegel DY, Shipley WU, et al. Long-term outcomes of selective bladder preservation by combinedmodality therapy for invasive bladder cancer: the MGH experience. Eur Urol 2012;61:705-11.

88. Mak KS, Smith AB, Eidelman A, et al. Quality of Life in Long-term Survivors of Muscle-Invasive Bladder Cancer. Int J Radiat Oncol Biol Phys 2016;96:1028-36.

89. Efstathiou JA, Bae K, Shipley WU, et al. Late pelvic toxicity after bladder-sparing therapy in patients with invasive bladder cancer: RTOG 89-03, 95-06, 97-06, 9906. J Clin Oncol 2009;27:4055-61.

90. Zietman AL, Sacco D, Skowronski U, et al. Organ conservation in invasive bladder cancer by transurethral resection, chemotherapy and radiation: results of a urodynamic and quality of life study on long-term survivors. J Urol 2003;170:1772-6.

91. Williams SB, Shan Y, Ray-Zack MD, et al. Comparison of Costs of Radical Cystectomy vs Trimodal Therapy for Patients With Localized Muscle-Invasive Bladder Cancer. JAMA Surg 2019;154:e191629.

92. International Collaboration of Trialists; Medical Research Council Advanced Bladder Cancer Working Party (now the National Cancer Research Institute Bladder Cancer Clinical Studies Group); European Organisation for Research and Treatment of Cancer Genito-Urinary Tract Cancer Group, et al. International phase III trial assessing neoadjuvant cisplatin, methotrexate, and vinblastine chemotherapy for muscle-invasive bladder cancer: longterm results of the BA06 30894 trial. J Clin Oncol 2011;29:2171-7.

93. Kun LE, Toohill RJ, Holoye PY, et al. A randomized study of adjuvant chemotherapy for cancer of the upper aerodigestive tract. Int J Radiat Oncol Biol Phys 1986;12:173-8.

94. Souhami L, Gil RA, Allan SE, et al. A randomized trial of chemotherapy followed by pelvic radiation therapy in stage IIIB carcinoma of the cervix. J Clin Oncol 1991;9:970-7.

95. Hagan MP, Winter KA, Kaufman DS, et al. RTOG 9706: initial report of a phase I-II trial of selective bladder conservation using TURBT, twice-daily accelerated irradiation sensitized with cisplatin, and adjuvant MCV combination chemotherapy. Int J Radiat Oncol Biol Phys 2003;57:665-72.

96. Miyamoto DT, Mouw KW, Feng FY, et al. Molecular biomarkers in bladder preservation therapy for muscleinvasive bladder cancer. Lancet Oncol 2018;19:e683-95.

97. Choudhury A, Nelson LD, Teo MT, et al. MRE11 expression is predictive of cause-specific survival following radical radiotherapy for muscle-invasive bladder cancer. Cancer Res 2010;70:7017-26.

98. Laurberg JR, Brems-Eskildsen AS, Nordentoft I, et al. Expression of TIP60 (tat-interactive protein) and MRE11 (meiotic recombination 11 homolog) predict treatmentspecific outcome of localised invasive bladder cancer. BJU Int 2012;110:E1228-36.

99. Magliocco AM, Moughan J, Simko J, et al. The impact of MRE11 in nuclear to cytoplasmic ratio on outcomes in muscle invasive bladder cancer an analysis of NRG/RTOG 8802, 8903, 9506, 9706, 9906, and 0233. J Clin Oncol 2017;35:343.

100. Walker AK, Karaszi K, Valentine H, et al. MRE11 as a Predictive Biomarker of Outcome After Radiation Therapy in Bladder Cancer. Int J Radiat Oncol Biol Phys 2019;104:809-18.

101. Yang L, Taylor J, Eustace A, et al. A Gene Signature 
for Selecting Benefit from Hypoxia Modification of Radiotherapy for High-Risk Bladder Cancer Patients. Clin Cancer Res 2017;23:4761-8.

102. Efstathiou JA, Mouw KW, Gibb EA, et al. Impact of Immune and Stromal Infiltration on Outcomes Following Bladder-Sparing Trimodality Therapy for Muscle-Invasive Bladder Cancer. Eur Urol 2019;76:59-68.

103. Song YP, McWilliam A, Hoskin PJ, et al. Organ preservation in bladder cancer: an opportunity for truly personalized treatment. Nat Rev Urol 2019;16:511-22.

104.Koga F, Kihara K, Yoshida S, et al. Selective bladdersparing protocol consisting of induction low-dose chemoradiotherapy plus partial cystectomy with pelvic lymph node dissection against muscle-invasive bladder cancer: oncological outcomes of the initial 46 patients. BJU
Int 2012;109:860-6.

105.Kijima T, Tanaka H, Koga F, et al. Selective tetramodal bladder-preservation therapy, incorporating induction chemoradiotherapy and consolidative partial cystectomy with pelvic lymph node dissection for muscle-invasive bladder cancer: oncological and functional outcomes of 107 patients. BJU Int 2019;124:242-50.

106. Rompré-Brodeur A, Shinde-Jadhav S, Ayoub M, et al. PD-1/PD-L1 Immune Checkpoint Inhibition with Radiation in Bladder Cancer: In Situ and Abscopal Effects. Mol Cancer Ther 2020;19:211-20.

107.Antonia SJ, Villegas A, Daniel D, et al. Overall Survival with Durvalumab after Chemoradiotherapy in Stage III NSCLC. N Engl J Med 2018;379:2342-50.

Cite this article as: Tholomier C, Souhami L, Kassouf W. Bladder-sparing protocols in the treatment of muscle-invasive bladder cancer. Transl Androl Urol 2020;9(6):2920-2937. doi: 10.21037/tau.2020.02.10 